\title{
Automation of physical experiments regarding explosions of air-methane mixtures
}

\author{
Adrian Bogdan Șimon-Marinică ${ }^{1 *}$, Zoltan Vass $^{1}$ \\ ${ }^{1}$ National Institute for Research \& Development in Mine Safety and Protection to Explosion - \\ INSEMEX Petroșani, 32-34 G-ral. V. Milea Street, Romania
}

\begin{abstract}
In the following study, experimental results are obtained from an automated stand. With the help of this experimental stand, visualization techniques such as Schlieren and Shadowgraph can be applied, to study the flame front propagation of air and inflammable gas mixtures initiation. In parallel, an infrared sensor was used to control a push-pull solenoid to open the gas escape diaphragm of the stand. To obtain the explosive gas mixture at various concentrations (between the lower explosion limit and the upper explosion limit) an original programmable mixer was used, based on computational algorithms for accurate control of stepper motors which allow attainment of air and inflammable gas flows in order to achieve a homogeneous and continuous mixture at the desired concentration. The performed experiments allow for a better understanding of the flame front production and propagation, facilitating the knowledge and optimization of the operating times from the reduction mechanisms for reducing the effects of explosions of the flammable gas-air mixtures.
\end{abstract}

\section{Introduction}

Types of gasses and mixtures of gasses are used in many industrial applications. By the help of gas mixers or by the use of gas blenders we can produce mixtures of gasses according to a predefined composition, instead of just using a premixed gas. These gas mixers have been used for a long time in industry and have been very useful in many applications. The technology behind these gas mixers has reached maturity and is very reliable. Continuous use of gas blenders offers numerous advantages over ready mixes, such as homogeneity, flexibility, economics. Gas mixing machines are used to produce gas mixtures of the highest quality. Benefits of the use of gas mixing machines are above all the consistent homogeneity of the gas mixtures. Process reliability is achieved from the consistent quality flow of the blended gas. Machines that produce gas mixtures can provide maximum flexibility from mixing ratio to gas quantity and place of use. The machine operator can produce the exactly needed gas mixture. Gas mixers vary widely in their ability to hold a mixed gas proportion accurately under various conditions. Higher quality gas mixers define their accuracy precisely in terms of flow rate, temperature conditions, and

\footnotetext{
* Corresponding author: bogdan.simon@insemex.ro
} 
a definition of "accuracy." Statements like "highly accurate" or "very precise" or "one percent accurate" are not meaningful unless the parameters are defined in technical terms.

\section{Concentration control using stepper motors}

Stepper motors are DC motors that rotate in precise increments or "steps". They are very useful when you need to position something very accurately. These stepper motors are controlled by applying pulses of direct current electricity inside their internal coils. These pulses provide rotation of the motor by one step, also known as micro stepping. Step by step motors have a magnetized geared core surrounded by a defined number of coils that acts as electromagnets. Usually only two coils are inside a step by step motor divided further into a small number of coils. To move the stepper motor shaft in a discrete number of steps we need to precisely control the current inside the coils, applying electricity in polarity energize one coil and then the motor shaft is attracted to the energized coil and it locks into place. Removing the electricity from one coil and applying it to the other coil of the stepper motor will cause the shaft to move to the second energized coil and to lock into place. Applying current to both coils in equal amount will cause the motor shaft to lock into place at halfway from the two coils also known as half step. This operating mode can be extended in order to create four steps, eight steps and even sixteenth steps. We can obtain this operating principle by controlling the ratio of the current that is applied to both coils which will cause the motor shaft to move to a position between the coils a position that is closer to one coil than the other. Precise positioning is obtained by the use of micro stepping that will move the motor shaft a fraction of a degree.

Stepper motors that are bipolar consist of two coils of wire and generally they have four connections, a number of two connections per coil. One big advantage of bipolar stepper motors is that they use the entire coil winding to be more efficient. In that case, bipolar stepper motors need a complex controller or a driver to operate.

Unipolar stepper motors also have two electrically coils, but each of the coils have a centered tap resulting three connections on each coil.

In a unipolar type stepper motor just half of each coil is used at one time. In every configuration the positive voltage is applied to the center tap and left there.

In order to attract the motor shaft a negative voltage is applied to one side of the coil, just like the case of bipolar stepper motor, unipolar stepper motors can advance one step when current is removed from the center tap of the coil and it is applied to the next side of the coil.

If we want to reverse the direction of a unipolar stepper motor, we don't need to reverse the polarity. It can be done by simply applying a negative voltage to the other side of the coil. In this case current will flow exactly in the opposite direction through the coil and will cause the stepper motor shaft to move in the opposite direction.

Stepper motors that are unipolar are a lot easier to control because they do not require reversing current polarity in order to change direction. In this case the unipolar stepper motor uses only half of the coil windings thus at a certain moment of time unipolar motors become less efficient due to wasting half of the coil wiring. Unipolar stepper motors are easier to control as there is no requirement to reverse current polarity to change direction. However, as the unipolar stepper motor only makes use of half of the coil windings at any given moment they are not as efficient as half of the wiring is essentially wasted. There are also stepper motors that can be wired as bipolar motors and unipolar motors. They are made out of four coils that can be joined together to create two center tap coils (in the case of unipolar configuration) or two coils (in the case of bipolar configuration). 


\section{Automatic system for stoichiometric mixture of air-methane}

The stoichiometric mixture of air-methane was achieved by using an automatic system [1], which is in continuous development and essential for gas mixtures experiments. It is based on stepper motors that precisely control the gas flows, into a direct realization of a mixture (explosive atmospheres) inside an experimental stand, as we can see in figure 1.
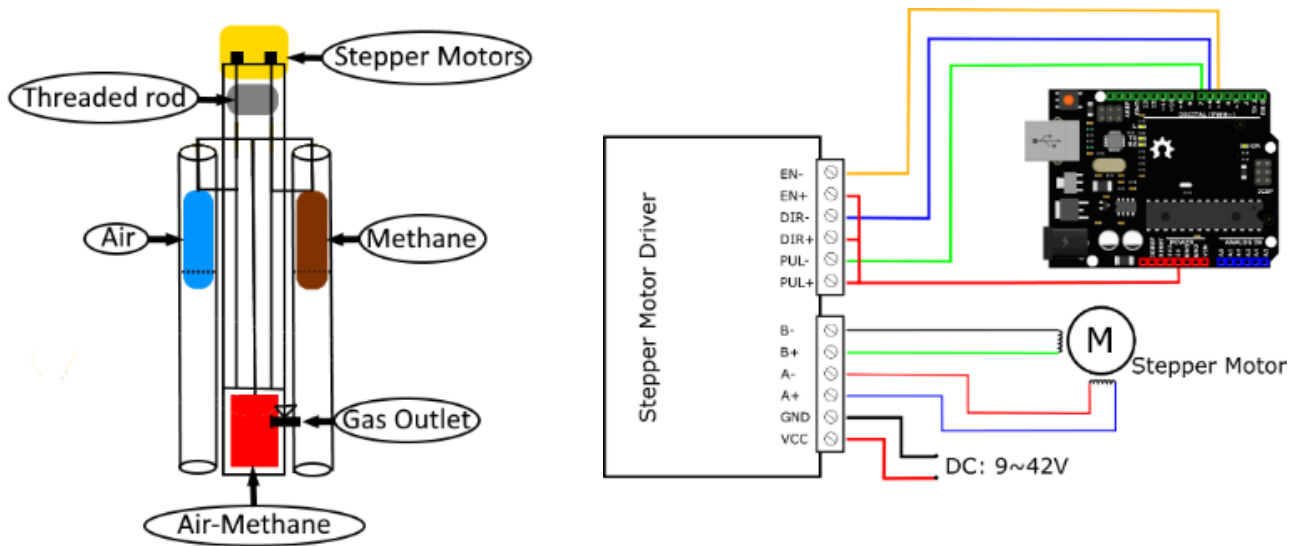

Fig. 1. Air-methane mixer operating principle

\subsection{System overview}

This paper presents the basics of a gas mixer machine that is driven by two simple stepper motors [2] yet powerful and they fit to a vast number of applications. The steppers have a step angle of $1.8^{\circ}, 1.7$ A current rating, $1.5 \Omega$ per coil, $2.8 \mathrm{MH}$ inductance and $40 \mathrm{~N} / \mathrm{cm}$ holding torque. The system overview can be observed in figure 2 .

The easiest way to use and run our stepper motors was to use a driver (a controller) and in our case a TB6600 driver [3] Arduino compatible was used. The stepper motor driver is a professional tool to use in projects that requires two phase stepping motors. This device is compatible with Arduino board and other develop boards that can support an $5 \mathrm{~V}$ digital signal output. The driver used in the current paper has a vast range of power input from $9 \mathrm{~V}$ to $42 \mathrm{VDC}$. It is capable to output $4 \mathrm{~A}$ peak current, that should be enough to drive all the stepper motors, also it can support speed control and direction. Through the control interface with six switches we can set up the micro steps (seven types of micro steps) and the output current (eight types of current control). All signal terminals got high speed optocoupler isolation, increasing the anti-high frequency interference ability. Being a professional control device, it can drive two phase stepper motors, four phase stepper motors or hybrid stepper motors.

In order to program and control the stepper motors an Arduino [4] board was used. Arduino developing board is a free open source platform that allows users to develop electronic projects. It consists of a physical programmable circuit board (referred as a microcontroller) and a software, or an integrated development environment (also known as IDE) that runs on a computer and it is used to write and upload computer code to the Arduino board. Regarding previous programmable circuit boards, Arduino does not need a separate hardware (that is called a programmer) to load code onto the board, this can be simply made by connecting the USB cable to the computer. In addition, the Arduino 
development environment comes with a simplified version of $\mathrm{C}++$ language, that makes it easier to learn coding.

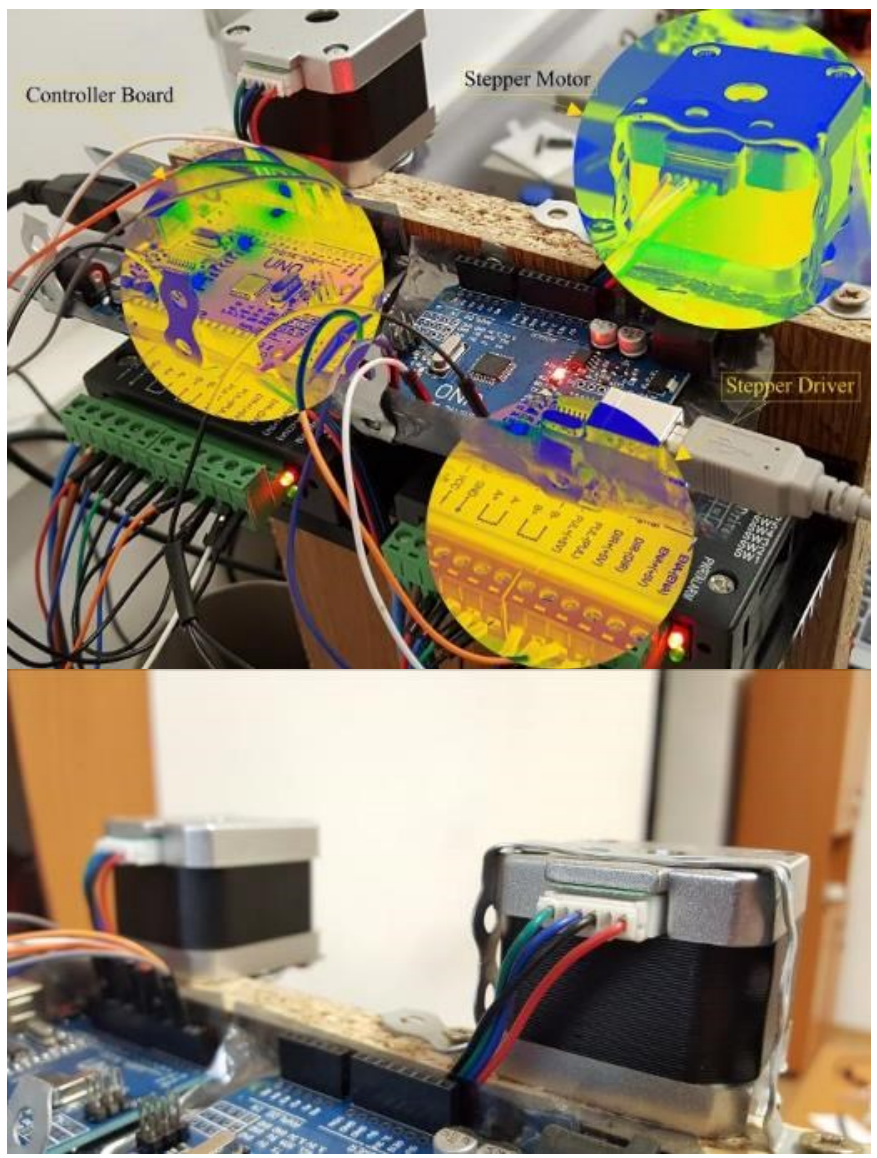

Fig. 2. Air-methane mixer assembly

\subsection{System inputs}

To reach a desired gas concentration default input parameter were needed for a short mathematical model. The cylinders that stores the methane and air in the purpose of blending have a maximum volume of $V M_{\text {aximum }}=3,5$ liters that is taken as an input parameter as well as $d=100 \mathrm{~mm}$ diameter of the cylinder. Total surface $S$ will be calculated as $\pi \mathrm{r}^{2} h$ resulting $S=7853,75$ square millimeters. The threaded rod has a M6 diameter that give us a step of $1 \mathrm{~mm}$ per spire. In other words, for one turn of 1 millimeter, $h=1$ millimeter will result a volume $V_{l}=h * S V_{1}=1 * 7853,75$ cubic millimeters or $V_{l}=$ 7, 85375 milliliters. Other static parameters will be time $\Delta t=120$ seconds and a total of blended gas of 1000 milliliters. Knowing the fact that for one stepper turn of 1 millimeter we can get 7,8 milliliters of blended gas we can proceed with the desired gas concentration calculus. If we desire for example a $10 \%$ volumic fractions of methane, $C_{l}=10 \%$ the first stepper motor will push 100 milliliters of pure methane $V_{C H 4}=100$ [ml]. To do that the stepper needs to rotate $n_{1 \text { turns }}=V_{C H 4} / V_{1}=100\left[\mathrm{mll} / 7,8[\mathrm{ml}]=>n_{1 \text { turns }}=12,82\right.$ [turns] at an angular speed of $G D_{1}=\left(n_{1 \text { turns }} * 360^{\circ}\right) / \Delta t=>\omega_{1}=\left(12,82 * 360^{\circ}\right) / 120[\mathrm{~s}]=>$ 
$G J_{1}=38,46[\% / s]$ angular speed. The second stepper motor will push 900 milliliters of air to dilute the methane $V_{A I R}=900[\mathrm{ml}]$. For this the stepper will rotate $n_{2 \text { turns }}=V_{A I R} / V_{l}=$ $900[\mathrm{ml}] / 7,8[\mathrm{ml}]=>n_{2 \text { turns }}=115,38$ [turns] at an angular speed of $G_{2}=\left(115,38 * 360^{\circ}\right)$ $/ 120[s]=>\mathrm{GO}_{2}=346,14[\mathrm{o} / \mathrm{s}]$

\section{Modelling of air-methane dilution}

Through the approach of Computational Fluid Dynamics (CFD) it is possible to solve physics problems by dividing space into small boxes called control volumes. In each control cell all variables are constant and derive from the flow balance and fluxes with the help of physics taking place inside each cell, all these variables eventually may change.

An explosion is defined by a very large amount of energy that is released in a short period of time. This release of energy can be done by pressure, temperature, radiation or even flying debris. At its origin an explosion can be physical or chemical by nature. The most common examples of physical explosion are lightning, steam pressure vessels and nuclear power. Regarding chemical explosion they are mostly caused by the detonation or deflagration of combustible mixtures of gas and air. Inside buildings most gas explosion come from leakage of explosive combustible gas. The fuel that can cause an explosion may be a combustible gas (or vapors), a mist of combustible liquid, a combustible dust, or some combination of these. The most common combination of two fuels is that of a combustible gas and a combustible dust, called a "hybrid mixture". Gas or dust explosions can be divided into two groups: deflagration and detonation.

When we discuss of a deflagration the continuation of the chemical reaction comes from the transport of heat. After the explosion the flame front will travel with a subsonic speed between 0.1 to 100 meters per second. It is very hard to establish the exact values for the propagation speed and it depends on many circumstances. If the explosive environment is homogeneous and undisturbed, an ignition point will produce a spherical flame front [5]. The reacted gas cloud during reaction of the release of energy it will double its original diameter.

High pressures that come in a shock wave cause a detonation with the continuation of the chemical reaction, travelling at a supersonic speed of 100 to 10000 meters per second. After initiation the flame front, starting with low speed will start to accelerate. In this scenario a transition of a deflagration to a detonation will occur, mainly in long pipelines or tunnels. A new phenomenon is produced turning deflagration pressure wave into a shock wave, phenomenon caused in generally by the dependence between the pressure and the speed of sound, meaning that the higher the pressure is and the temperature, the higher the speed will be and the same in the other way around.

The output from a simulation with CFD-models has few limitations. Output may be either pressures, flames or any other parameter modelled, either as a 2D/3D field plot of one variable at one or more (movie) time steps or transient pressure traces at certain locations or wall panels

\subsection{Pre-processing with geometry development and mesh generation}

Any CFD flow problem starts with the preparation of geometry using CAD software, as well as dividing the geometry into cells, called the mesh or grid before any modelling is done. Different mesh strategies exist: structured, unstructured, hybrids, composite and overlapping meshes. The choices of numerical methods (discretization equations) and models to be used, and meshing strategies, are strongly interdependent. The success of simulation depends on appropriate choices for most CFD problems. 
To visualize the pre-mixed flow gas, a basic flow geometry was developed that simulates the air-methane jet streams into chamber, as seen in the figure below.
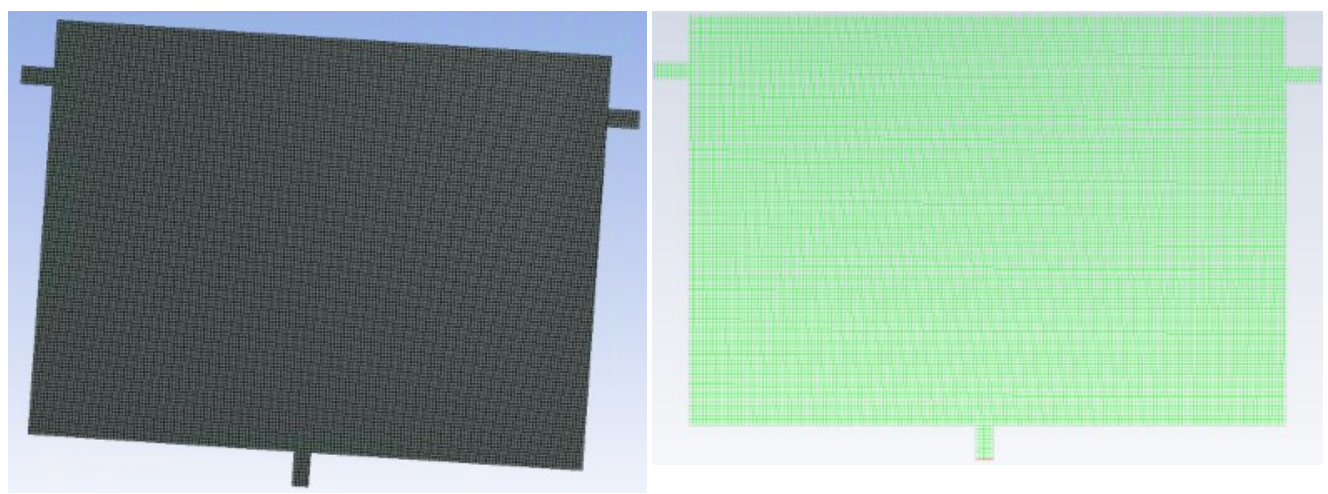

Fig. 3. Mesh generation of air-methane chamber

The geometry in figure 3 comes with the following dimensions: 174 millimeters length, 120 millimeters width and 70 millimeters height resulting a volume of 1000 milliliters.

The generated mesh uses cells of $1 \times 1 \times 1$ millimeters, to achieve a good accuracy for the output data, resulting a number of 20068 cells for the mesh generation and a 65 seconds simulation time.

\subsection{Steps in Computer Simulation}

The flow of a fluid [6] in a conduit may be laminar flow or it may be disorderly flow. In the case of a laminar flow the fluid will always flow with reduced mixing of fluid particles. If inside the flow is introduced a dye, it will not blend with the fluid and it will retain its identity for a long period of time. Viscous shear stress always influences a laminar flow. follows:

After the necessary geometry is created the simulation process [7] can start as

○ Import geometry; set boundaries and regions; mesh the geometry; define the physical models; define the region conditions, values and boundary conditions; set up reports; run the simulation; post-process the results.
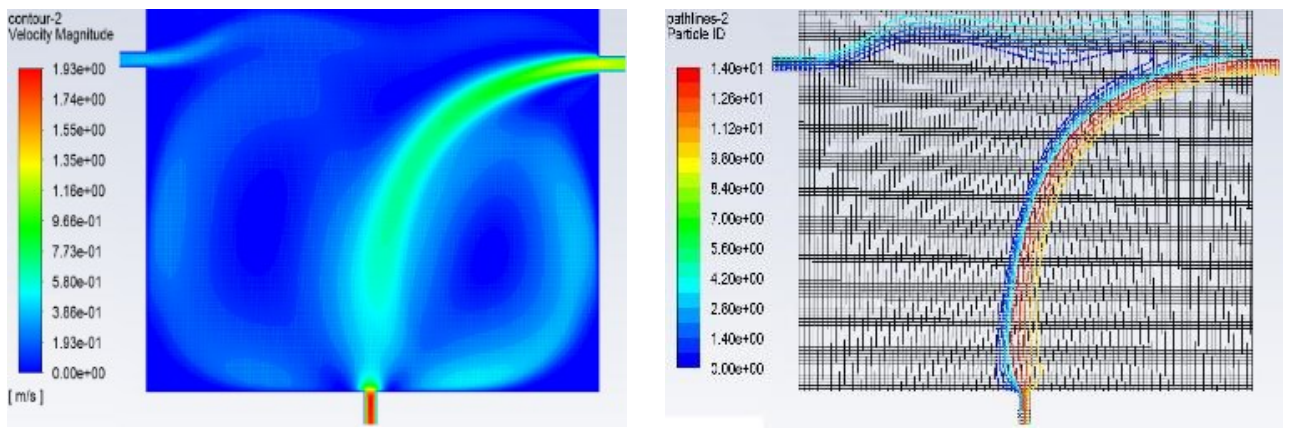

Fig. 4. Air-methane dilution with mesh and particle flow 

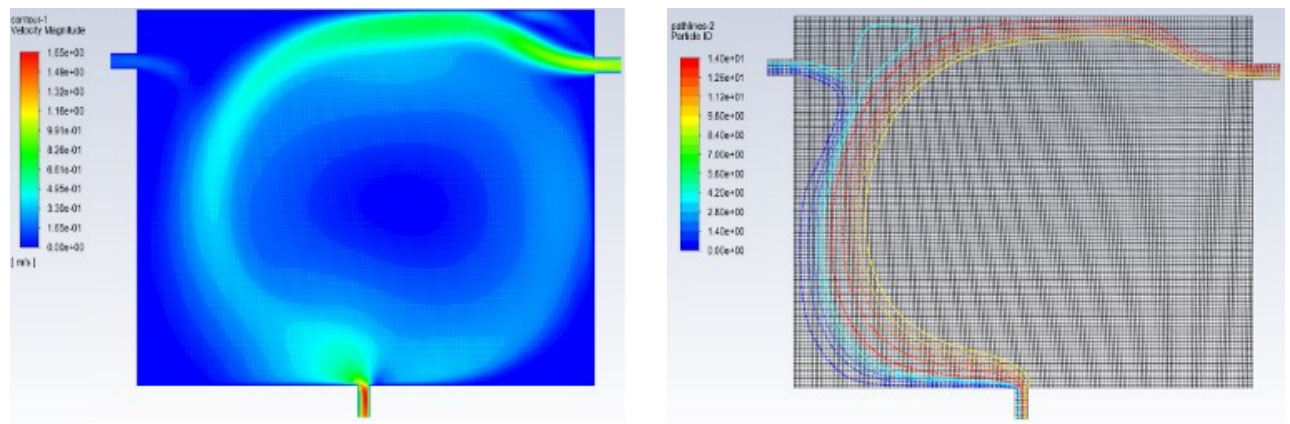

Fig. 5. Air-methane dilution

\section{Conclusions}

The main objective of this paper was to develop an automated system for air-methane mixtures regarding gas concentration input that is further used in physical experiments carried out in experimental stands for the research of initiation of explosive atmospheres [8]. The air-methane flow pattern obtained by CFD method, as it can be seen in figures 4 and 5 look similar with the physical results obtained by the experimental stand presented at the beginning of the paper.

This paper was developed within the Nucleu-Programme, carried out with the support of Romanian Ministry of Research and Innovation, project no. PN-19-21-01-05, project title: Fundamental research and computer simulations on the initiation of explosive gas mixtures by potential sources of ignition of a different nature (in Romanian: Cercetări fundamentale și simulări computerizate privind inițierea amestecurilor gazoase explozive prin surse potențiale de aprindere de natură diferită).

\section{References}

1. Șimon A. B., Ghicioi E., Vlasin N., Florea D., Vass Z., Programming and use of stepper motors in research of air-methane explosive atmospheres, Proceedings of the 20th Young people and multidisciplinary research ISYPMR 2018, Romania, pp 17-22, 2018;

2. Open Impulse, 42BYGHW609 Stepper Motor Datasheet, Available on https://www.openimpulse.com/blog/document-viewer/?pdf_file=42BYGHW609-Stepper-MotorDatasheet1.pdf

3. DFRobot V.1.2, Stepper Motor Driver User Guide, Available on https://forum.arduino.cc/index.php?action=dlattach;topic=558523.0; ;ttach=266385

4. Arduino User Guide, Getting Started with Arduino and Genuino products, Available on http://www.arduino.cc/en/Guide/HomePage/

5. Vlasin N., Ghicioi E., Florea D., Vass Z., Chiuzan E., Researches regarding gas explosions by combined imagistic methods, Proceedings of the 18th International Multidisciplinary Scientific Geoconference SGEM 2018, Bulgaria, Vol. 18, pp 777-783, 2018;

6. Dan Gh. Ionescu, Introduction to Fluid Mechanics, Edition II, Technical Publishing, Bucharest, 2005

7. Ansys, Inc. ANSYS FLUENT Tutorial Guide, Release 14.5, Octomber 2012

8. A.B. Șimon-Marinică, E. Ghicioi, N. I. Vlasin, M. C. Șuvar G. D. Florea, 19th International Multidisciplinary Scientific Geo Conference - SGEM 2019 Conference Proceedings, 1165- 1171 (2019). 